\title{
Development of Sustainable Partnership Organizational Mechanism (POM): Case of Local Action Groups (LAG)
}

\author{
Vilma Atkociuniene $^{1, *}$, Sigitas Vaitkevicius ${ }^{1}$ and Egle Stareike ${ }^{2}$ \\ 1 Business and Rural Development Management Department, Bioeconomy Development Faculty, \\ Agriculture Academy, Vytautas Magnus University, Universitetas Str. 10-402, 53361 Kaunas, Lithuania; \\ sigitas.vaitkevicius@vdu.lt \\ 2 Department of Law, Public Security Academy, Mykolas Romeris University, Maironio Str. 27, \\ 44211 Kaunas, Lithuania; egle.stareike@mruni.eu \\ * Correspondence: vilma.atkociuniene@vdu.lt
}

check for updates

Citation: Atkociuniene, V.; Vaitkevicius, S.; Stareike, E. Development of Sustainable Partnership Organizational Mechanism (POM): Case of Local Action Groups (LAG). Sustainability 2021, 13, 11672. https://doi.org/ $10.3390 /$ su132111672

Academic Editor: Christian Vandenberghe

Received: 13 September 2021

Accepted: 20 October 2021

Published: 22 October 2021

Publisher's Note: MDPI stays neutral with regard to jurisdictional claims in published maps and institutional affiliations.

Copyright: (c) 2021 by the authors. Licensee MDPI, Basel, Switzerland. This article is an open access article distributed under the terms and conditions of the Creative Commons Attribution (CC BY) license (https:// creativecommons.org/licenses/by/ $4.0 /)$.

\begin{abstract}
The study of the partnership organization mechanism (POM) aims to answer the question of how an organization manages the mechanical operation of the partnership and how the partnership system shapes itself in order to achieve a fairer balance across all junctions of the POM, through shafts connected into a single mechanism. The study has led to a deeper understanding of the empirical operation of the POM and has led to the identification of 20 POM configuration principles, the harmonization of which, in accordance with the principle of coherence, enables sustainability to be achieved and managed. The study is exploratory and therefore empirical facts supporting theoretical insights were sought. The information database of the study consists of 5-year observation data of Lithuanian local action groups, exploratory survey data and in-depth interviews for verification of the phenomenon. The empirical study allowed us to verify the theoretical operation of the POM and helped us to determine the content and purpose of the relationships between different groups of stakeholders in the region. A total of 10 POM empirical models have been detected, which confirmed the fundamental thesis of the study that sustainability can be managed by ensuring the harmonious operation of the system and by controlling the level of system coherence.
\end{abstract}

Keywords: partnership organization mechanism; sustainability; local action groups

\section{Introduction}

Sustainability has been widely discussed in various contexts. It is important because it defines the principles for ensuring the stability of the social system through its internal balance and coherence with the external environment. This is the only way to ensure the long-term viability of the system and to ensure that its efficiency is not lost in the long term. Sustainability also includes an in-depth analysis of systemic factors that determine the recovery of biological, natural, social or economic systems after a partial exhaust due to the effects of internal or external factors. The ability to recover and rebuild is critical to the long-term survival of a system, so in the long run, those systems are sustainable that are able not only to maintain a higher efficiency, but also to rebuild exhausted internal and external resources, and thus, they ensure the stability of resources. All this can be recognized in the biological form of commensalism and the higher biological form of mutualism [1]. The essence of the first is the use without causing harm to the environment and the essence of the second is the use by creating environmental benefits. The first explains the preservation of the environment in which the system operates in its original state, and the second explains its evolution into a more advanced one.

Sustainability is related to the resilience of a system [2]. In order to achieve greater resilience with minimal costs, the scientific literature proposes a coherent framework for sustainability and resilience. Resilience determines the ability of a system to respond to external threats [3] and to withstand the negative effects of the environment and internal 
and external destruction. This is the organizational reliability of a system [4], which is related to strengths, activities and entrepreneurship inherited from people [5], a system's ability to survive and adapt to difficult conditions. This feature of the system is explained by the study of the biological nature of the system. It shows that the biological nature of a system is derived primarily from its human or natural nature.

Biological nature is important because it contains the most important factor for longterm survival - natural evolution. It is biological nature that is characterized not only by the ability to change, but also by the ability to adapt and reorganize itself, which guarantees the biological system long-term viability. Organizations are characterized by this feature as well. Being composed of people, they inherit organizational reflexes through human resources from individuals and on the basis of them form their own organizational reflexes, which ensures a more effective adaptation and functioning in changing conditions [6]. This increases the resilience of the organization and ensures sustainability.

An in-depth study of organizational reflexes has shown that a social and at the same time economic system that is recognized as an organization not only has an arc of organizational reflexes characteristic of living organisms, including humans, but also continuously improves itself through human resources. Organizational reflexes explain how the system coordinates, teaches and reconfigures itself in order to achieve a greater performance and a more optimal balance of actions, which it needs to be more sustainable but at the same time more efficient in the long term.

In a social system, when it comes to community and its partnerships, the resilience arises not only from the systemic functioning of its biological nature, but also from social connections and social mechanisms (behavior, decisions and actions) [7], which are important in overcoming difficulties and recovering after them. Therefore, proper resilience management is the best way to increase sustainability in the long term.

This study includes a feature that is equally important for the first two features of a sustainable system-the coherence [8]. In order to ensure sustainability, it is not sufficient to guarantee the adequacy and stability of resources, or to ensure the resilience of the system alone. It is still necessary to guarantee that its operation will be sustainable and coordinated. This will protect against the over exhaustion of resources at any stage of the system operation, and will lead to better performance and will ensure that all actions within the system will become more coordinated. The literature presents an approach that coherence is not a permanent state of the system, but develops in response to external and internal factors [9]. In addition, when examining the concept of coherence, it was noticed that coherence is also compatible with the principles of mechanical operation [10], which suggests that, at a certain period in time, coherence can nevertheless be treated as a relatively permanent state of the system.

Arenas, Díaz-Guilera, Kurths, Moreno, Zhou (2008) [11] treated a coherence as absolute, and at mechanical operation the coherence means the synchronous operation of several elements, whether they are a whole or only a part of the system. In addition, mechanical operation explains the permanence of the system when it comes to maintaining system efficiency at the same level [12]. This study examined for the organizational mechanism of partnership operating in the local action groups (LAG) and provided evidence that cooperation between social stakeholders can be defined on the basis of mechanical laws. The latter study was limited to attributing the mechanical principles to the organizational mechanism of partnership. The study did not answer the question of how the mechanical operation is managed in the organizational mechanism of the partnership and how the partnership system shapes itself in order to achieve a fairer balance between all junctions of the partnership organizational mechanism through its shafts.

Compared with previous research, this paper presents the study of partnership organizational mechanism phenomena. The study allowed a deeper theoretical and empirical understanding of operation principles of the partnership organizational mechanism (POM). The 20 initial configurations of POM were developed during this study and it was found 
that by combining initial configurations of POM, the desired level of sustainability can be achieved.

An empirical study conducted in local action groups allowed us to verify the theoretical operation of the POM and helped us to determine the content and purpose of the relationships between different groups of stakeholders in the region. A total of 10 POM empirical models were identified, which confirmed the fundamental thesis of the study, that sustainability can be managed by ensuring the coherent operation of the system and by controlling the level of sustainability.

This study is exploratory, and therefore has sought empirical facts supporting theoretical insights. The reference database of the study consists of 5-year observation data of local action groups, exploratory survey data and in-depth interviews used for phenomenon verification.

\section{Materials and Methods}

\subsection{Organizational Mechanism}

Signs of mechanism management can be found as early as the second decade of the XXI century. In management studies, the principles of the design of mechanisms are analyzed in an attempt to adapt them to the structure of organizations [13]. Studies are carried out and questions are raised as to which mechanism is most suitable for achieving objectives such as social well-being, development of areas, efficiency of solutions, etc. Is there a need for the state regulation? If so, which mechanism is most appropriate for this? What activities of the mechanism are required by the institutions, i.e., common rules and procedures for decision-making?

The most prominent theory is the theory of mechanism design, which is understood as an "engineering" part of economic theory. The founder of mechanism design theoryHurwicz (1973) [14] - grounds the theory in economic institutions, which are considered information systems, and their participants send messages, the totality of which determine the allocation of certain resources. According to the author, a mechanism is an institution, a procedure (as if specific rules of the game) designed to achieve results. Hurwicz [14] was one of the first to use the term incentive compatibility, which today also describes the coherent functioning of the stakeholders in achieving their goals.

A derivative of Hurwicz's (1973) [14] mechanism design theory is Maskin's (2002) [15] implementation theory. This theory is the part of mechanism design theory that covers the problem of the presence of an "inferior" balance in conjunction with the desired balance. It is this theory that grounds the partial coherence, or the partial operation, of the mechanism, which is detectable today in mechanical units such as the car's gearbox. The managerial meaning of its operation is that the gearbox, being a mechanism as one unit, actually accumulates several different alternatives within itself, thanks to which the organization can move slowly but surely or quickly. Namely, Maskin's (2002) [15] implementation theory allows social stakeholders not only to be seen as a synchronous whole, but also to contribute to the perception that their functioning can be controlled, and the fragments of their functioning that are remote from the holistic model are nothing more than functional connections that help social systems, such as local action groups, to achieve intermediate goals.

The discourse mechanism design theory is an analytical framework that is set up by the institutions to highlight the problem of incentives. The "developers" of the mechanism are members of the society, organization, or institution and others who, in accordance with their mission, activate the relevant nodes of the mechanism (junctions) and combine them into a single chain (shaft) guaranteeing their synchronous operation, which is necessary to achieve effective co-operation and to ensure the coherent functioning of the system.

Formally, the problem of incentives was determined by the implementation of social choice rules, which in sustainability represent the purpose of sustainability and the tasks of the participants in relation to their long-term environment-friendly evolution, which promotes the survival not only of them but also of their surrounding environment. 
The rules of social choice specify, for each specific situation, which results would be socially optimal in the relevant environment (state, city, rural area). In this discourse, if a mechanism has features where the set of equilibrium results are equal to the socially optimal results (determined by the rules of social choice), then it can be concluded that the rules of social choice are implemented by this mechanism [15-17].

There are distinguished formal and informal mechanisms of governance (Figure 1), which are defined by stakeholder representation, the division of powers and accountability [18-20]. Through achieving local development goals and environmental change, formal and informal governance mechanisms should be combined with each other (e.g., stakeholders must be represented, not only by formal authorities, but also by informal organizations (network organizations, rural communities, etc.) (Figure 1), which becomes relevant in laying the foundation for system sustainability.

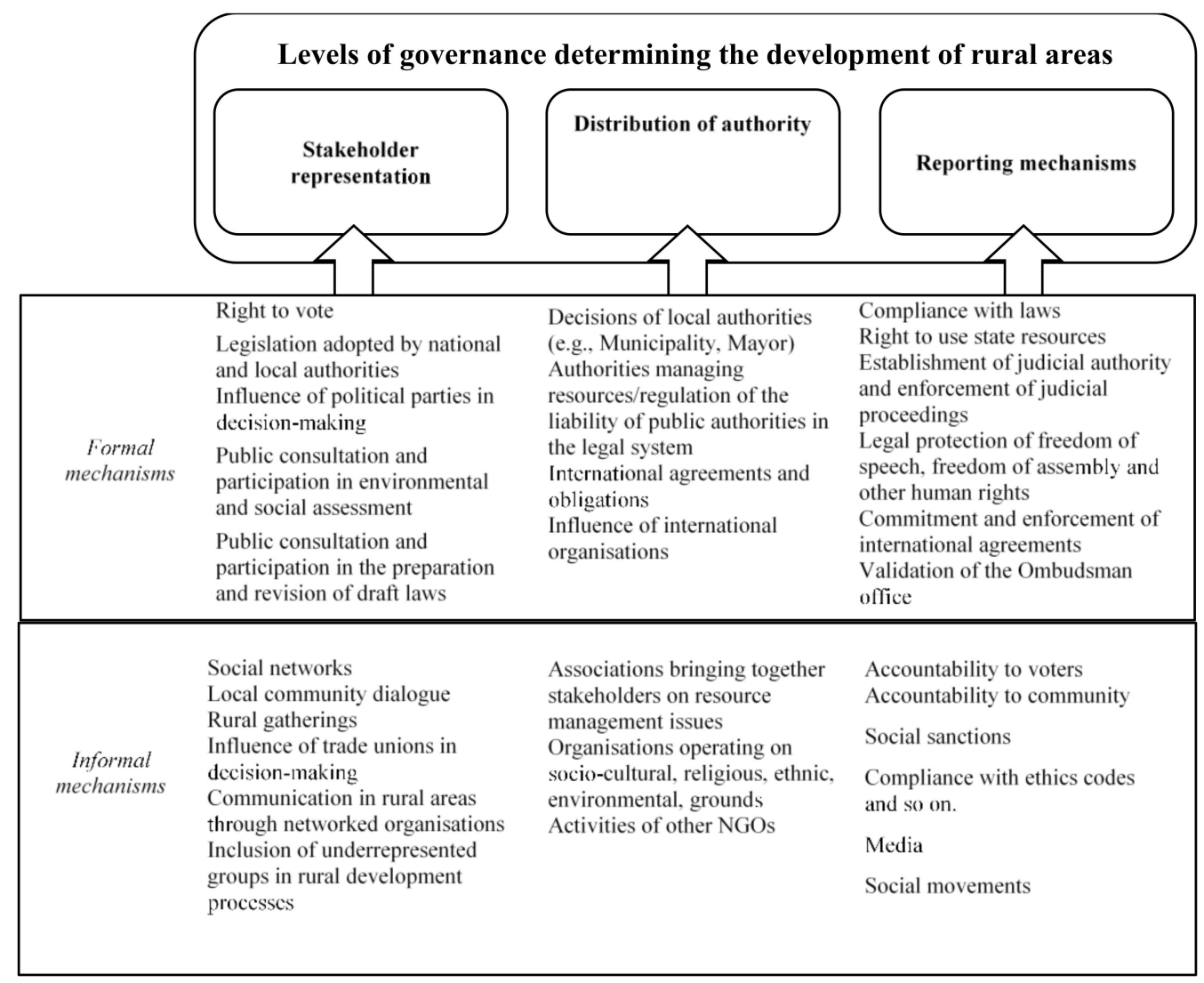

Figure 1. Formal and informal mechanisms determining rural development. Source: [12].

The mechanism in the social system can be compared with rotating gears, the operation of which can explain why one element is related to another, how the elements interact with each other, what their connections are [21] and how the system's cohesive operation is synchronized.

In the outlook of situational theory, the activity of the organization is determined not only by the formal structure of the organization, but also by the relationship of the organization to the external environment, technologies, and organization strategy, the ratio of the information available and the corresponding situation, and other factors. Namely, the mechanisms (they manage information flows, establish rules, etc.) which ground the emergence of coherent and harmonious organizations [22].

According to Hedstrom and Swedberg (1998) [23], the concept of mechanisms in the social sciences can be perceived as a set of hypotheses that allow us to explain social phenomena-interactions between stakeholders or between stakeholders and some social factors. There are three main mechanism models [23,24]: (1) situational mechanisms, which 
are systematically accurate, having the social structure and macro-sociological qualities, revealing the stakeholder beliefs, goals or prospects; (2) the action of forming mechanisms which exist at the micro level, and enabling an analysis as relevant stakeholder beliefs, goals or opportunities generated by the specific actions; and (3) transformation mechanisms, which include stakeholder interactions and reveals how stakeholder objectives are transformed into collective outcomes.

\subsection{POM Sustainability Discourse}

The origins of the organizational mechanism of the partnership can be considered as the development of management theories. This is because all theories of organizational management essentially talk about how to balance and manage people's actions in an organization, which inevitably relates to the principles of coordination of their activities, optimization of their efforts and partnership.

Mechanism perception is recognizable in bureaucracy theory [25]. A bureaucratic organization, because of its bureaucratic apparatus, most effectively controls the work of many people when they seek specific defined goals.

According to Weber (2015) [25], bureaucracy is a centralized form of organization management that acts as the most efficient management mechanism based on rationality. The essence of this form is the organization of human activity through systematic processes and a clear hierarchical mechanism, which is also relevant in modern perspectives of sustainability and sustainability as a premise of optimized socio-economic efficiency, intuitively forming the foundation of formal mechanistic regularities in the knowledge of social phenomena. The model of an ideal bureaucratic organization eventually became the basis for examining the interaction of decision-making and the bureaucratic mechanism with other institutions and public sector problems. However, this is not the only theory grounding the mechanistic perception of system operation. Bennis (1968) [26] introduced Adhocracy theory which is opposed to Weber's theory of bureaucracy, which breaks down the formalized structure, creating a rational mechanistic basis for the formal mechanism of management. However, at the same time, W. Bennis's (1968) [26] theory of Adhocracy focus on multidisciplinary teams united by their own functions, which form the basis for the formation of the non-formal management mechanism and the development of partnership perception and deeper knowledge [26].

In addition to the aforementioned cooperative systems introduced by Chester (1938) [27], later, the administrative behavior discussed by Herbert (2013) [28] laid the foundation for Systems management theory, the perception of which is very important and will later expand the boundaries of mechanistic perception. Systems management theory focuses not on Weber's [25] bureaucratic apparatus and not on Bennis' [26] multidisciplinary team and its functions, but on the perception of business wholeness, which is unique in that the business consists of components of the whole that must operate in harmony in order for the system to function optimally. Systems management theory is based on entropy, synergy and holistic concepts, which are the basis for an open system composed of open and closed subsystems. The latter theory refers to the concept of partnership and coherence through synergy, holism and subsystems and creates assumptions for sustainability through entropy by defining the trend of system decay.

In the context of these and earlier mechanistic theories, Stareike (2017) [12] constructs the organizational mechanism of partnership. She named the basic characteristics of the organizational mechanism of the partnership: the mechanisms consist of the activities and interactions of subjects (interested persons); they are designed to perform certain actions and functions; the models of the organizational mechanism describe the corresponding characteristics of the mechanisms that operate in organizational processes. Certain models of organizational mechanisms operate in the relevant organizational processes; the organizational mechanism may be associated with, or may change, the organizational management structure. 
Stareike (2017) [12] describes the organizational mechanism of the partnership as a whole of solutions, also known as junctions and activities that connect them into shafts, acting synchronously with each other. The author identifies the junctions of the organizational mechanism as the relevant activities of the mechanism, and the shafts of the organizational mechanism are called the links between the components (connections that connect the relevant activities to each other). The simultaneous execution of several activities in the chain are described by Stareike (2017) [12] as a synchronous operation.

Although Stareike (2017) [12] does not examine the organizational mechanism of the partnership in the context of coherence and sustainability, as in bureaucratic, Adhocracy and systematic theory, this link is easily identified through a partnership which is defined as a self-organizing non-hierarchical alliance through which stakeholders at different levels of governance-i.e., businesses and local communities-share common goals, benefits, resources, skills and risks [29-34]. In rural areas, the partnership is based on the principle of synergy and the competitive advantage of stakeholders [35]. The objectives of the organization of partnership within the partnership's organizational mechanism for the development of rural areas relate to a pooling of resources, their sustainable consumption, ensuring sustainability, inclusion of communities, strengthening of regions, creating jobs, and reducing social exclusion, etc. The organizational mechanism of the partnership is, from a procedural point of view, information, consultation, inclusion and participation activities and the links between them (Table 1).

Table 1. Roles of POM junctions.

\begin{tabular}{|c|c|c|c|}
\hline \multicolumn{4}{|c|}{ The Role of Junction * } \\
\hline Information & Consulting & Inclusion & Participation \\
\hline $\begin{array}{l}\mathrm{I}_{1}-\text { Communication } \\
\mathrm{I}_{2} \text {-Direction } \\
\mathrm{I}_{3} \text {-Initiation } \\
\mathrm{I}_{4} \text {-Introduction }\end{array}$ & $\begin{array}{l}\mathrm{C}_{1} \text {-Expression of opinion } \\
\mathrm{C}_{2}-\text { Knowledge transfer } \\
\mathrm{C}_{3} \text {-Recommendation } \\
\mathrm{C}_{4} \text {-Advice on how to proceed } \\
\mathrm{C}_{5} \text {-Presentation of an expert or } \\
\text { specialist opinion }\end{array}$ & $\begin{array}{l}\mathrm{Ic}_{1}-\text { Bringing together } \\
\mathrm{Ic}_{2}-\text { Cooperation } \\
\mathrm{Ic}_{3}-\text { Empowerment } \\
\mathrm{Ic}_{4}-\text { Motivation } \\
\mathrm{Ic}_{5}-\text { Pooling of resources }\end{array}$ & $\begin{array}{l}\mathrm{P}_{1} \text {-Information exchange } \\
\mathrm{P}_{2} \text {-Development of dialogue } \\
\mathrm{P}_{3}-\text { Representation } \\
\mathrm{P}_{4}-\text { Discussion } \\
\mathrm{P}_{5}-\text { Conciliation } \\
\mathrm{P}_{6}-\text { Negotiation }\end{array}$ \\
\hline
\end{tabular}

* Stareike (2017) [12].

In partnership organizational mechanisms, information activities were taken over by Benington, Geddes (2013) [34] and are designed to introduce community members to a possible partnership. It is the transfer of information about possible ways of engaging the informed person in community decision-making and self-realization when not seeking feedback from the informed person.

Consulting activities include specialist advice in response to the questioner's inquiry about community processes. Consulting is complex and includes economic, financial, sociological, socio-psychological, psychodynamic, anthropological constructs, as well as theories of organization development, political and practical aspects, cultural values, and norms of behavior [36]. The result of the consultation is the sharing of professional information, advice or assistance in determining the goals of the organization and solving the problems that arise [37].

Inclusion is intended to help stakeholders involved in community-based processes to acquire resources and opportunities from those who can provide them or facilitate their exchange with those who need them in order to participate in economic, social and cultural life in a sustainable way and to meet society's accepted standards of well-being and living [38]. In most cases, inclusion is limited in time to get operational as soon as possible, so stakeholders are involved through network structures or existing regional/local organizations. Inclusion creates the preconditions for stakeholders to participate in management processes, thus creating the preconditions for coherence arising from a set of synchronized actions. 
Participation-the presence of the persons concerned as an active participant in the pursuit of community and the conduct of activities with the social partners and community members. Participation in the partnership includes mechanisms for the adoption and coordination of top-down and bottom-up development initiatives [38]. Participation also includes consultations with community representatives, meetings with the public, etc. [39,40].

In partnership, informational, consulting, inclusion and participation as a basis for their interaction, links between stakeholders are formed (Table 1). Through these links, potential risks and benefits are distributed among stakeholders. Partnership improves cooperation, trust and innovation between stakeholders. The response and responsibility of stakeholders to changes depends on the ability of organizations to inform, consult and include them in management processes [41].

Rethinking the POM factors identified by Stareike (2017) [12] showed that the coherence is not formed as an individual function of the junction, but as the interaction of the junction with others through the shafts. After looking into the POM factors identified by Stareike (2017) [12] and linking them to the experience of the management theories discussed above, it has been observed that depending on the connections, interactions can be: single, multiple, unidirectional and multidirectional.

Single-action is when the connection is only of one shaft. These are: $\mathrm{I}_{2}$-Direction; $\mathrm{I}_{3}$-Initiation; $\mathrm{I}_{4}$-Introduction; $\mathrm{C}_{3}$ - Recommendation; $\mathrm{C}_{4}$-Advice on how to proceed; $\mathrm{Ic}_{4}$-Motivation.

Multi-action is when the connection is of two or three shafts. These are: $\mathrm{I}_{1}-$ Communication; $\mathrm{P}_{1}$-Information exchange; $\mathrm{P}_{2}$-Development of dialogue; $\mathrm{P}_{3}$-Representation; $\mathrm{P}_{4}$-Discussion; $\mathrm{P}_{5}$ - Conciliation; $\mathrm{P}_{6}$-Negotiation; $\mathrm{C}_{1}$ - Expression of opinion; $\mathrm{C}_{2}$-Knowledge transfer; $\mathrm{C}_{5}$ Presentation of an expert or specialist opinion; $\mathrm{Ic}_{1}$-Bringing together; $\mathrm{Ic}_{2}-$ Cooperation; $\mathrm{Ic}_{3}-$ Empowerment; Ic 5 -Pooling of resources (see Table 2).

Table 2. Core drivers of POM.

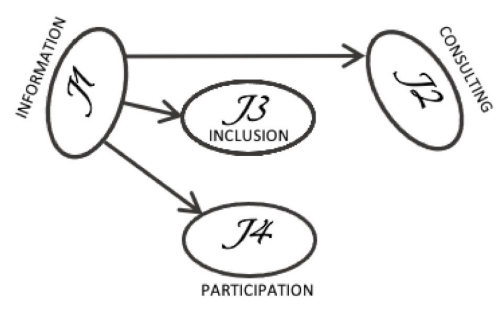

$\mathrm{I}_{1}$ - Communication

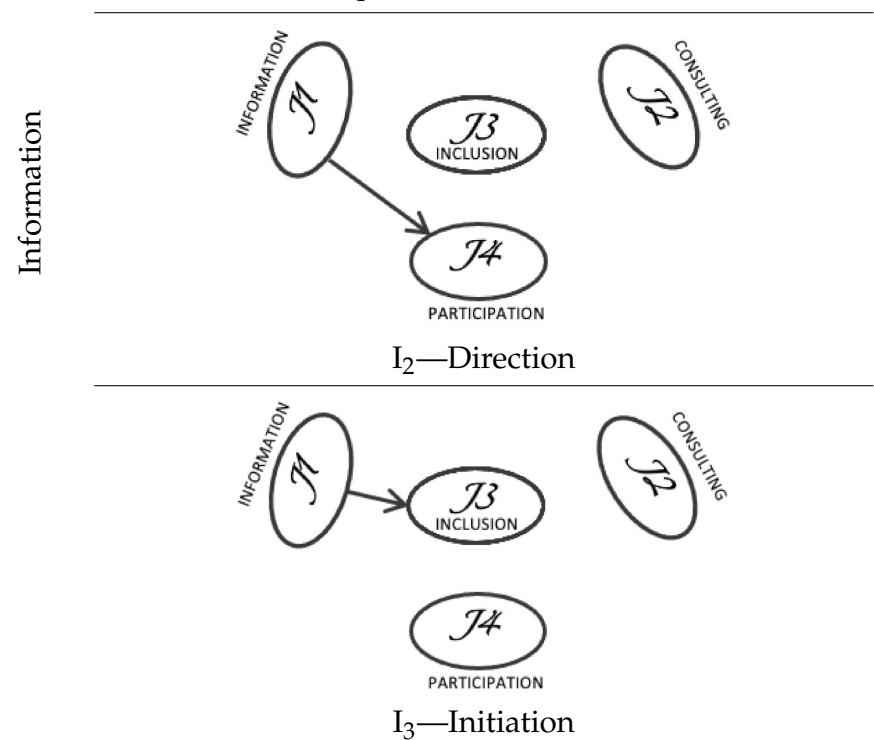

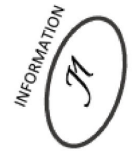

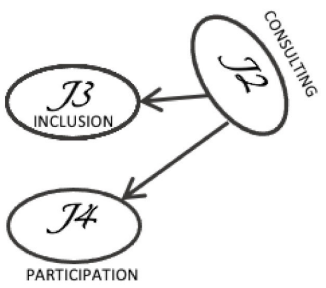

$\mathrm{C}_{1}$-Expression of opinion

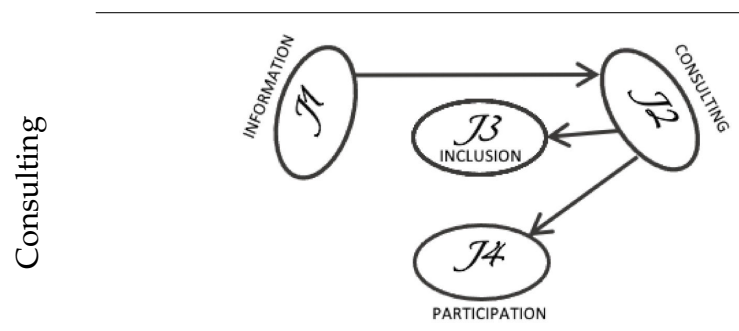

$\mathrm{C}_{2}$-Knowledge transfer

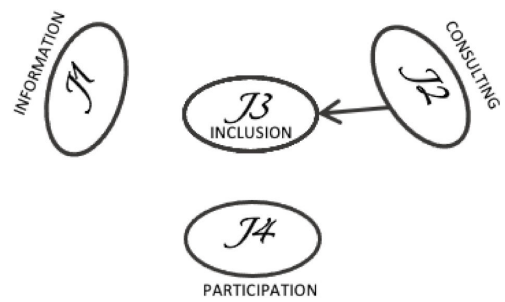

$\mathrm{C}_{3}$-Recommendation 
Table 2. Cont

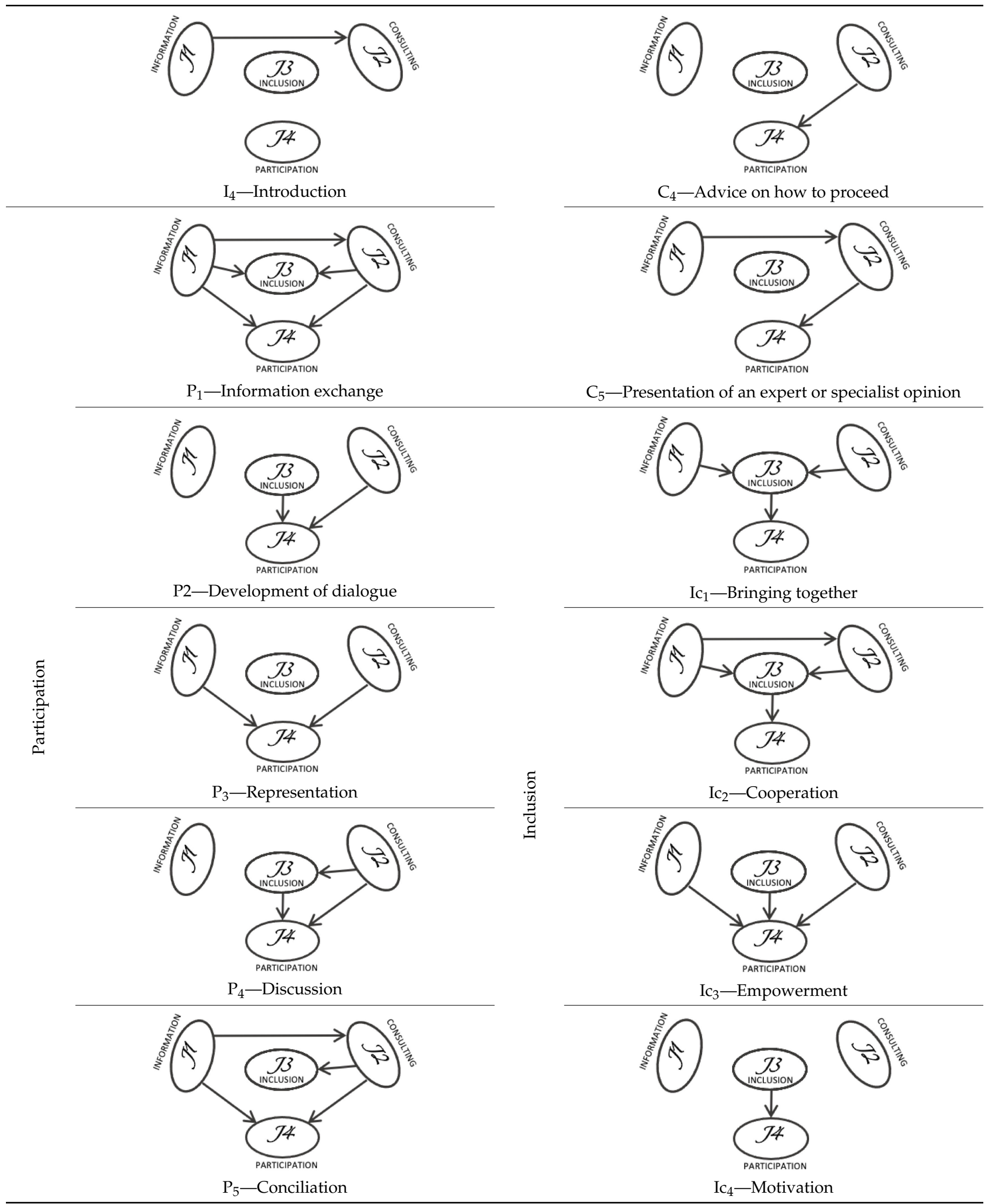


Table 2. Cont.
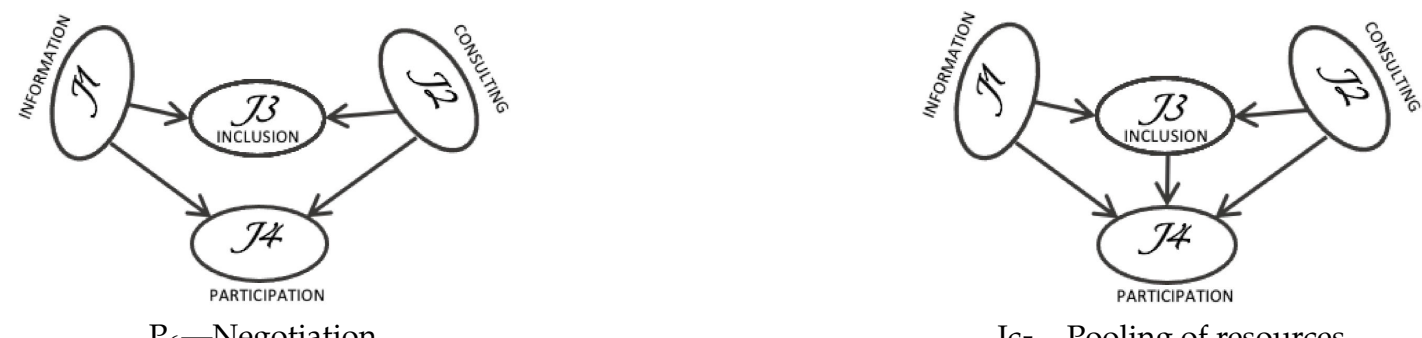

$\mathrm{P}_{6}$-Negotiation

Ic 5 -Pooling of resources

Arrows represent shafts connecting an active junction. Unconnected junctions in presented models are inactive.

Unidirectional is when the junction in relation to others is only the result. These are: $\mathrm{J}_{2}$ (consulting), $\mathrm{J}_{3}$ (Inclusion), and $\mathrm{J}_{4}$ (participation) junctions in $\mathrm{I}_{1}-$ Communication; $\mathrm{J}_{4}$ (participation) in $\mathrm{I}_{2}$-Direction; $\mathrm{J}_{3}$ (Inclusion) in $\mathrm{I}_{3}$-Initiation; $\mathrm{J}_{2}$ (consulting) in $\mathrm{I}_{4}$ Introduction; $\mathrm{J}_{3}$ (Inclusion), and $\mathrm{J}_{4}$ (participation) junctions in $\mathrm{C}_{1}$-Expression of opinion, and in $\mathrm{C}_{2}-$ Knowledge transfer; $\mathrm{J}_{3}$ (Inclusion), and $\mathrm{J}_{4}$ (participation) junctions in $\mathrm{P}_{1}-$ Information exchange; etc. (Table 2).

Multidirectional is where the junction is both a factorial and a resultant. These are: $\mathrm{J}_{2}$ (consulting) junction in: $\mathrm{C}_{2}-$ Knowledge transfer; $\mathrm{C}_{5}$-Presentation of an expert or specialist opinion; $\mathrm{Ic}_{2}$-Cooperation; $\mathrm{P}_{5}$-Conciliation; $\mathrm{J}_{3}$ (Inclusion) junction in: $\mathrm{P}_{4}$-Discussion; $\mathrm{Ic}_{1}$-Bringing together; $\mathrm{Ic}_{2}$-Cooperation; Ic $\mathrm{C}_{5}$-Pooling of resources (see Table 2).

For a study of Sustainable Partnership Organizational Mechanisms (POMs) in local action groups (LAG), the Stareike (2017) [12] developed POM was used (Figure 2). Rethinking it, the POM system of essential drivers was revised and a system of graphical symbols (Table 2) was created, which was tested during an expert in-depth study, but the complex model itself remained unchanged.

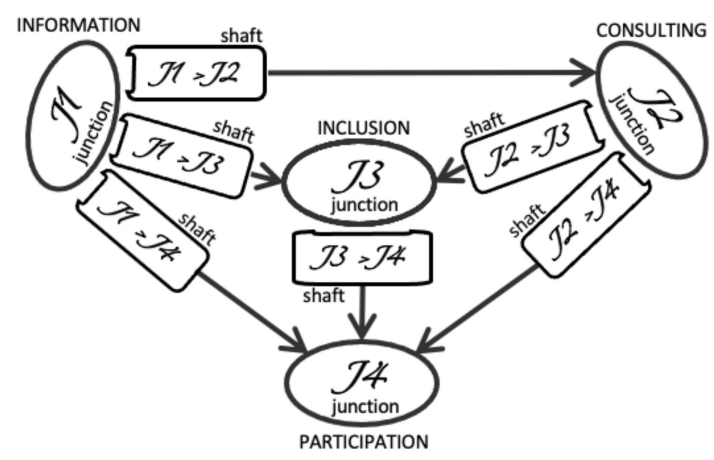

Figure 2. Complete shaft drive model of the partnership organizational mechanism.

The Stareike (2017) [12] model was used for typological modelling of POM mechanistic experiences in this research, but was tested, not in the complex operation of the model as performed by Stareike (2017) [12], but the structure of the POM core drivers and the typology of its internal relationships developed during rethinking.

\subsection{Methods of the Research}

The survey of the LAG administration, LAG board, LAG members and external experts was conducted using by a Stareike (2017) [12] validated questionnaire. The study data were processed by the SPSS program (version 24). The license holder was Vytautas Magnus University.

In total, $63 \%$ of existing LAG representatives and $57 \%$ of external experts invited to the study were interviewed. When the questionnaires were sent out, each LAG was asked to distribute at least five questionnaires among its members, apportioned between the LAG administration, the LAG board and the LAG members. No nests were created 
among the experts because all the experts were selected in such a way that their individual expertise was related to the knowledge of the LAG. The survey method was used to study the organizational mechanism of the partnership.

A questionnaire was prepared for the study of the design of the components of the organizational mechanism of the partnership.

The questionnaire examined how information, consultation, inclusion and participation activities affect each other and how much they are implemented in community activities, where stakeholders act as partners in the LAG. The statistical validity of the study data was assessed by Factor and Reliability analysis methods. Statistics of indices exhibited in Tables 3-5.

The structure of the variables in the questionnaire is given in Tables $3-5$. The syntax of the primary variables in the questionnaire was 'How much important is to [direct] [that it would be possible] [to consult]?' for J1-1 shaft (see Table 3), 'How much important is to [direct] [that it would be possible] [to include]?' for J1-2 shaft, and 'How much important is to [direct] [that it would be possible] [to inspire to participate]?' for J1-3 shaft. Latent variables (J1-1, J1-2, J1-3) created by Principal component analysis using the Varimax rotation method and used a Regression method to create a variable. In step two, shafts from latent variables using the same methods were joined into the junctions.

Reliability analysis was used to measure dispersion of each latent variable. There were no statistically significant differences between variables. The dispersion of all of them is informally similar. None of the latent variables have significantly more or less dispersed information content compared to others.

Consulting junction and its shafts are constructed analogously to Information Junction and its shafts. The difference is that the Information Junction consists of three shafts (Table 3) and the Consulting Junction consists of two shafts (Table 4). This is because the Stareike (2017) predictive model shows that the Consulting junction depends on information, but does not impact on the information junction, but like the Information Junction, the Consulting Junction makes an impact on Inclusion and Participation junctions. The results of the previous survey confirmed this hypothetical statement and showed that Information is the initiating variable and Consulting is the realizing one; therefore, in the tested model, the relationship between them was constructed and initially investigated as unidirectional.

Table 3. Validity and Reliability for Information Junction.

\begin{tabular}{|c|c|c|c|c|c|c|c|c|c|}
\hline \multicolumn{10}{|c|}{ J1 Information } \\
\hline \multirow{3}{*}{$\begin{array}{l}\text { Primary } \\
\text { variables }\end{array}$} & \multicolumn{6}{|c|}{ That it would be possible: } & \multirow{3}{*}{$\begin{array}{c}\text { Latent } \\
\text { variables }\end{array}$} & \multirow{3}{*}{$\begin{array}{l}\text { Factor } \\
\text { score }\end{array}$} & \multirow{3}{*}{$\begin{array}{l}\text { Corrected } \\
\text { Item-Total } \\
\text { Correlation }\end{array}$} \\
\hline & \multicolumn{2}{|c|}{ To Consult (J1-1) } & \multicolumn{2}{|c|}{ To Include (J1-2) } & \multicolumn{2}{|c|}{$\begin{array}{l}\text { To Inspire to Participate } \\
(J 1-3)\end{array}$} & & & \\
\hline & $\begin{array}{l}\text { Factor } \\
\text { score }\end{array}$ & $\begin{array}{l}\text { Corrected } \\
\text { Item-Total } \\
\text { Correlation }\end{array}$ & $\begin{array}{l}\text { Factor } \\
\text { score }\end{array}$ & $\begin{array}{l}\text { Corrected } \\
\text { Item-Total } \\
\text { Correlation }\end{array}$ & $\begin{array}{l}\text { Factor } \\
\text { score }\end{array}$ & $\begin{array}{l}\text { Corrected } \\
\text { Item-Total } \\
\text { Correlation }\end{array}$ & & & \\
\hline Direction & 0.831 & 0.648 & 0.901 & 0.816 & 0.901 & 0.814 & & & \\
\hline $\begin{array}{l}\text { Knowledge } \\
\text { transfer }\end{array}$ & 0.813 & 0.649 & 0.867 & 0.765 & 0.843 & 0.725 & $\begin{array}{l}\text { To Consult } \\
(J 1-1)\end{array}$ & 0.686 & 0.464 \\
\hline Introduction & 0.804 & 0.641 & 0.877 & 0.779 & 0.927 & 0.859 & $\begin{array}{l}\text { To Include } \\
(J 1-2)\end{array}$ & 0.969 & 0.877 \\
\hline \multirow[t]{3}{*}{$\begin{array}{l}\text { Leading } \\
\text { towards }\end{array}$} & 0.738 & 0.549 & 0.895 & 0.809 & 0.865 & 0.759 & $\begin{array}{c}\text { To Inspire to } \\
\text { Participate } \\
(J 1-3)\end{array}$ & 0.920 & 0.876 \\
\hline & \multirow[b]{2}{*}{ KMO } & \multirow{2}{*}{$\begin{array}{c}\text { Bartlett's Test } \\
\text { of Sphericity } \\
\text { Sig. }\end{array}$} & \multicolumn{3}{|c|}{ Extraction Sums of Squared Loadings } & \multirow{2}{*}{$\begin{array}{l}\text { Cronbach's } \\
\text { Alpha }\end{array}$} & \multicolumn{3}{|c|}{ Inter-Item Correlations } \\
\hline & & & & & $\begin{array}{c}\% \text { of } \\
\text { Variance }\end{array}$ & & Mean & Minimum & Maximum \\
\hline$J 1-1$ & 0.611 & 0.000 & & & 63.574 & 0.802 & 0.513 & 0.355 & 0.640 \\
\hline$J 1-2$ & 0.844 & 0.000 & & & 78.372 & 0.907 & 0.711 & 0.656 & 0.742 \\
\hline$J 1-3$ & 0.839 & 0.000 & & & 78.282 & 0.904 & 0.709 & 0.605 & 0.799 \\
\hline $\begin{array}{c}J 1 \\
\text { Information }\end{array}$ & 0.506 & 0.000 & & & 75.211 & 0.826 & 0.612 & 0.378 & 0.926 \\
\hline
\end{tabular}


Table 4. Validity and Reliability for Consulting Junction.

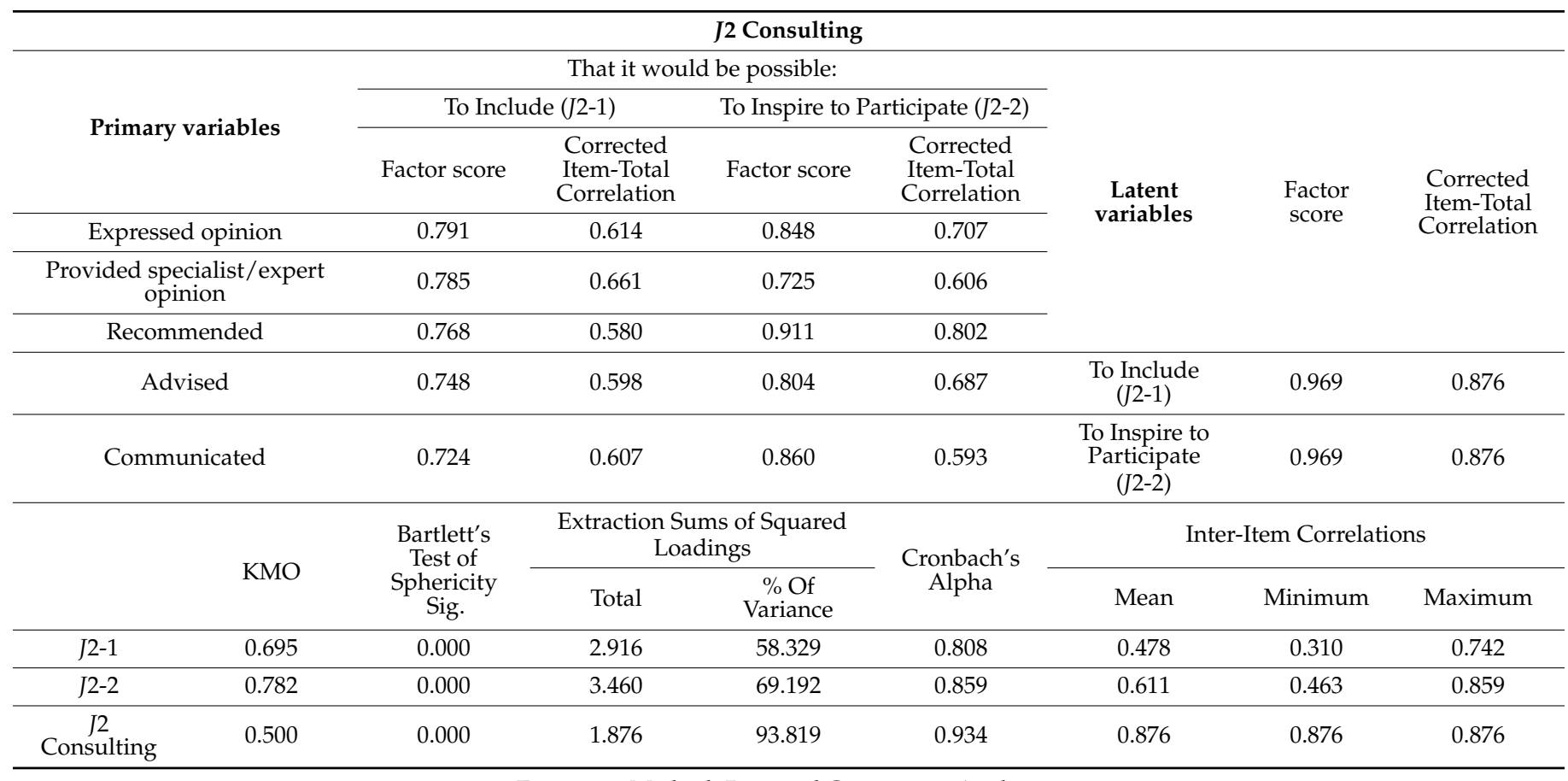

Extraction Method: Principal Component Analysis.

Table 5. Validity and Reliability for Partnership Organization Mechanism and Inclusion and Participation Junctions.

\begin{tabular}{|c|c|c|c|c|c|c|c|c|}
\hline \multicolumn{9}{|c|}{ Partnership Organisation Mechanism (POM) } \\
\hline \multirow{4}{*}{$\begin{array}{l}\text { J3 Primary } \\
\text { variables }\end{array}$} & \multirow{2}{*}{\multicolumn{2}{|c|}{$\begin{array}{l}\text { That it would be possible: } \\
\text { To Inspire to Participate (J3 } \\
\text { Inclusion) }\end{array}$}} & \multirow{3}{*}{$\begin{array}{l}\text { J4 Primary } \\
\text { variables }\end{array}$} & \multirow{2}{*}{\multicolumn{2}{|c|}{$\begin{array}{l}\text { By Participating ( } / 4 \\
\text { Participation) }\end{array}$}} & \multirow{5}{*}{$\begin{array}{c}\text { Latent } \\
\text { variables }\end{array}$} & \multirow{5}{*}{ Factor score } & \multirow{5}{*}{$\begin{array}{l}\text { Corrected } \\
\text { Item-Total } \\
\text { Correlation }\end{array}$} \\
\hline & & & & & & & & \\
\hline & \multirow[t]{2}{*}{ Factor score } & \multirow{2}{*}{$\begin{array}{l}\text { Corrected } \\
\text { Item-Total } \\
\text { Correlation }\end{array}$} & & Factor score & $\begin{array}{l}\text { Corrected } \\
\text { Item-Total } \\
\text { Correlation }\end{array}$ & & & \\
\hline & & & Communicated & 0.783 & 0.627 & & & \\
\hline $\begin{array}{l}\text { Bringing } \\
\text { together }\end{array}$ & 0.894 & 0.799 & $\begin{array}{l}\text { Developing } \\
\text { dialogue }\end{array}$ & 0.770 & 0.586 & & & \\
\hline Cooperation & 0.587 & 0.456 & Represented & 0.590 & 0.443 & $\begin{array}{c}J 1 \\
\text { Information }\end{array}$ & 0.866 & 0.757 \\
\hline Enabling & 0.828 & 0.704 & Debated & 0.822 & 0.681 & $\begin{array}{c}J 2 \\
\text { Consulting }\end{array}$ & 0.888 & 0.791 \\
\hline Motivated & 0.890 & 0.788 & Reconciliation & 0.674 & 0.557 & J3 Inclusion & 0.885 & 0.788 \\
\hline \multirow[t]{3}{*}{$\begin{array}{l}\text { Pooling } \\
\text { resources }\end{array}$} & 0.821 & 0.713 & $\begin{array}{c}\text { Ongoing } \\
\text { negotiations }\end{array}$ & 0.759 & 0.648 & $\begin{array}{c}J 4 \\
\text { Participation }\end{array}$ & 0.850 & 0.735 \\
\hline & \multirow{2}{*}{$\mathrm{KMO}$} & \multirow{2}{*}{$\begin{array}{l}\text { Bartlett's } \\
\text { Test of } \\
\text { Sphericity } \\
\text { Sig. }\end{array}$} & \multicolumn{2}{|c|}{$\begin{array}{c}\text { Extraction Sums of Squared } \\
\text { Loadings }\end{array}$} & \multirow{2}{*}{$\begin{array}{l}\text { Cronbach's } \\
\text { Alpha }\end{array}$} & \multicolumn{3}{|c|}{ Inter-Item Correlations } \\
\hline & & & Total & $\begin{array}{c}\% \text { Of } \\
\text { Variance }\end{array}$ & & Mean & Minimum & Maximum \\
\hline J3 & 0.832 & 0.000 & 3.297 & 65.939 & 0.866 & 0.562 & 0.344 & 0.817 \\
\hline$J 4$ & 0.643 & 0.000 & 3.259 & 54.319 & 0.810 & 0.446 & 0.206 & 0.793 \\
\hline$O M P$ & 0.812 & 0.000 & 3.044 & 76.098 & 0.895 & 0.681 & 0.600 & 0.755 \\
\hline
\end{tabular}

Extraction Method: Principal Component Analysis.

The partnership organizational mechanism (POM) consists of four junctions: J1 Information, J2 Consulting, J3 Inclusion, J4 Participation (Table 5). The Inclusion Junction differs from the previous ones in that its construct is based on only one shaft; therefore, unlike the Information Junction and the Consulting Junction, primary factor analysis was used for shaft and junction development. In the Inclusion Junction and the Participation Junction, cases secondary factor analysis were not performed. The Participation Junction 
and the Inclusion Junction differ because in the model, the Participation Junction does not affect any of the other junctions. In its construction, it has no shaft integrated. Because the syntaxis in the questionnaire for these questions differ, for J4 Participation primary variables it was "How much is important to [communicate] [by participating]?". This allowed us to present it as an endpoint in the model for the respondent and it is valid based on the results.

The designed instrument allows the identification of POM in the local action group (LAG). In addition, this construction enabled him to carry out a typological modelling of the OMP experiences of LAG representatives using the k-mean cluster analysis.

\subsection{Methodology for Typological Modelling of Partnership Organizational Mechanisms}

The study of the organizational mechanism of the partnership allowed the initial classification of mechanisms. It was carried out to assess which types of POMs exists in the practice of the LAGs studied.

Based on theoretical assumptions, the modelling was performed using all six shafts to assess the opinion expressed by experts on the intensity of application of the shaft in the partnership. The clusters based on the six-shaft configuration allowed us to determine the identity of the mechanism. A total of ten mechanism models were constructed to explain the operation of empirically identified mechanisms and their fragments.

Increasing the objectivity of the interpretation, the shaft indicators have been calculated on the z-scale and the k-mean cluster method was used for classification. The maximum value of the shaft together with the insignificantly distant values of other shafts were interpreted as the dominant features of the detected type. Shaft points significantly distant from the maximum value in the models were denoted as a dotted line connecting shaft components in the typological figures (Figures 3-11) and were interpreted as non-existing features in the model. Shaft values assigned to a group of significantly larger values are marked in typological diagrams as integral lines connecting shafts to the relevant junctions.

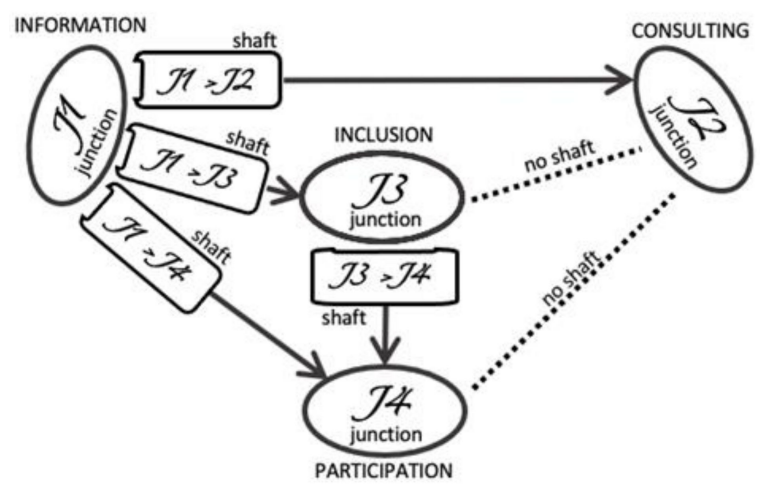

Figure 3. Incentive POM model.

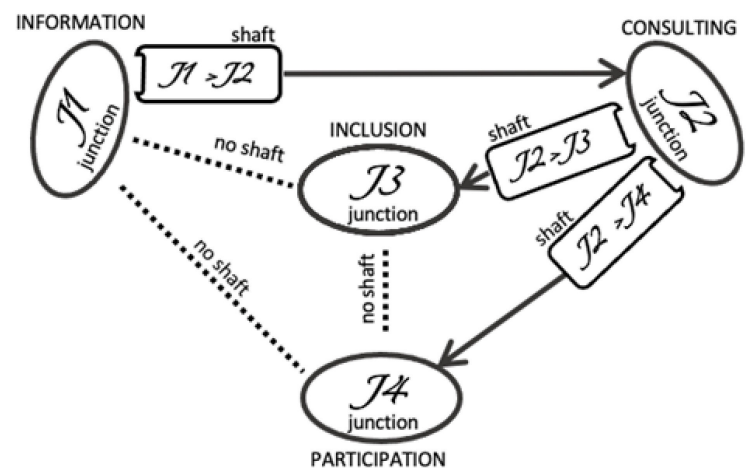

Figure 4. Knowledge transfer POM model. 


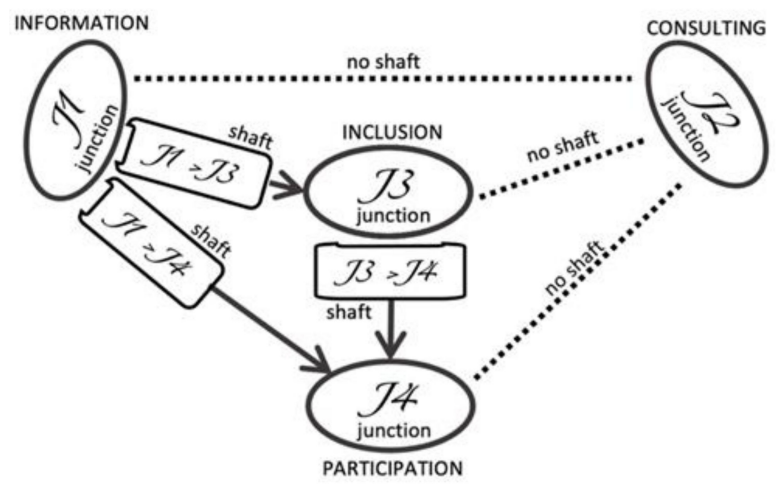

Figure 5. Employment POM model.

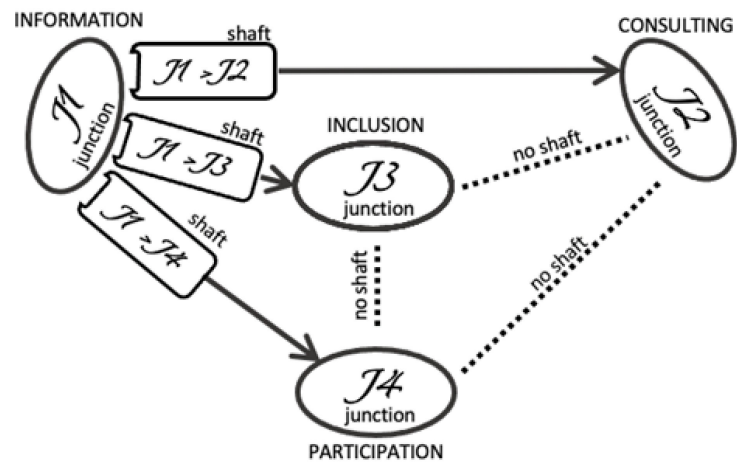

Figure 6. Communication POM model.

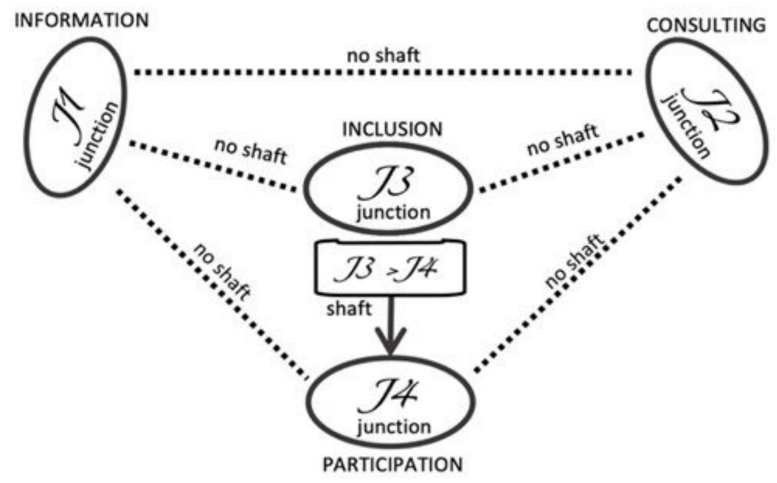

Figure 7. Motivation POM model.

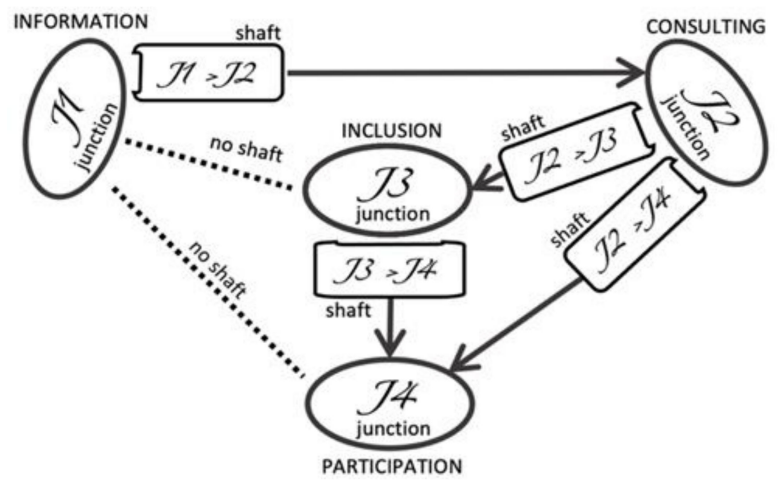

Figure 8. Engage in POM model. 


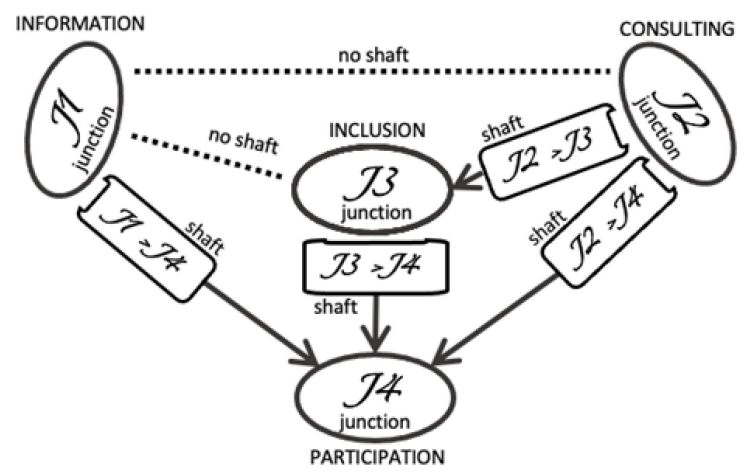

Figure 9. Familiarization POM model.

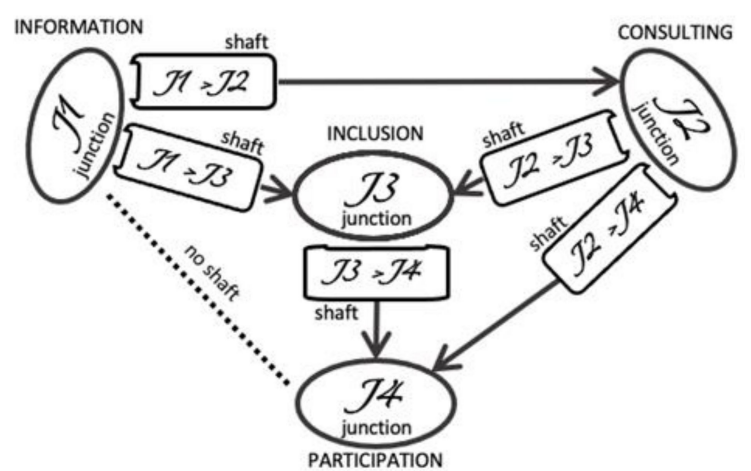

Figure 10. Support POM model.

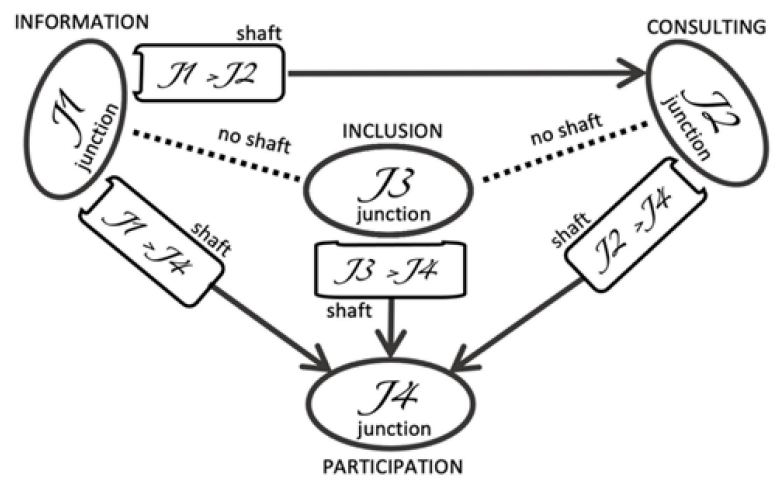

Figure 11. Involvement POM model.

\subsection{Outline of Long-Term Observation}

The organizational mechanism of the partnership has been studied for four years. LAG activities were observed through a combination of different data collection methods. First, interviews were conducted, then the LAG was communicated by consulting them and initiating a discussion about their experience during organized trainings. The primary purpose of the communication was to initiate the sharing of experience to help solve problems and to strengthen key competencies; the secondary purpose was to gather and systematize knowledge about the POM phenomenon by identifying and evaluating its features and their change during POM evolution.

Long-term observation allowed us to know the changes of POM during the growth of LAG competence and allowed us to capture the transformation of POM during the merging of several LAGs and the subsequent evolution of the complex unit.

Since the entire study is exploratory, the result describes the phenomenal features of POM. The study does not reflect the regularities of the prevalence of the phenomenon in the studied population, despite of the fact that some trends were observed. The observed trends 
were consistent not only with the theoretically identified POM operational principles, but also replicated the operational principles of other similar objects, the regularity of which has been scientifically and widely discussed in the scientific literature. Therefore, the observed trends are interpreted as the fact of the existence of the phenomenon, without assessing the prevalence of the fact in the population.

\subsection{Multimethod-Based Design}

The whole four-year study was separated into three phases: identification of phenomenon, description of the phenomenon, and distribution of the phenomenon qualities across the population. The long-term observation was focused on the first two phases, the survey into the second and third phases of this study. The long-term observation was selected because it was proved to be a useful tool for the development of theories and for an exploration of unknown phenomena in such mixed method designs like the Grounding Theory. In our case, it allowed us to clarify the phenomenon of POM and distinguish it from other phenomena in the first phase of research. It was also used for the identification of specific POM characteristics and for the identification of hypothetical POM diversity based on the number of identified characteristics.

The survey was used for the classification of POM into groups based on their dominant characteristics. Together with long-term observation, it allowed us more precisely to define the POM diversity and led into an explanation of how each POM operates.

The multimethod-based study design allowed us to estimate the POM variety and to explain the purpose of each POM and the fundamentals of its operation.

\section{Results}

Classification allowed us to identify two of the main empirical types of POM models. The first is unbalanced, to which the models are assigned with one or more passive junctions not connected to each other. The second is balanced, in which all the junctions are active and affect each other. Balanced models include both models: with all shafts and those with only a part of all the possible shafts.

\subsection{Unbalanced Models of POM}

In an empirical study, in the LAG, there were detected Incentive, Knowledge transfer, Employment, Communication, Motivation models (Figures 3-7). These models are characterized by a structure of one (Communication (Figure 6), Motivation (Figure 7)) and two (Incentive (Figure 3), Knowledge transfer (Figure 4), Employment (Figure 5)) active junctions. In-depth study of these models leads to the explanation that models with one active junction can be called unidirectional; with two active junctions-bidirectional; and with three or more active junctions-multidirectional.

The study also discovered that unidirectional models were used in specific cases not only as an organizational mechanism for partnership, but also as a tool of increasing competitiveness. This perhaps suggests that the defragmentation of the organizational mechanism of the partnership creates the preconditions for commercializing the relationship and for separating personal benefits from the social value that is being created. The profit maximization trend observed in suchlike POM was more pronounced than the needs and sustainability of the region. As a result of this effect, POM imbalance was observed, the intensiveness of which decreased with the increasing activity of the junctions.

Since the study was exploratory, an answer was sought as to whether the individual operation of the junctions can be attributable to POM. The study separated cases that could be treated as partnership from those that operate in a traditional benefit-based commercial relationship. This article presents only the models defined as partnership models.

The incentive model (Figure 3) includes Communication, Direction, Initiation, Introduction, and Motivation. Its purpose is to encourage and facilitate inclusion. It has been observed in LAG with a relatively lower organizational experience, i.e., in groups that have less experience of participation and a lack experience of attracting financing 
instruments. It was such groups that tended to focus more on preparation than on the implementation of activities. There was much more exchange in information material, insights, and established contacts and connections.

The knowledge transfer model (Figure 4) includes Introduction, Expression of opinion, Recommendation, Advice on how to proceed, and Presentation of an expert or specialist opinion. In several of the LAGs studied, it, like other POMs, was identified as a partnership model. However, a more detailed analysis of it revealed that in it, an Introduction, which in other POMs behave as an information function used to direct stakeholders to a partnership, did in fact act as a function of consultative advertising, the purpose of which is to position the client in the client's consulting program. In this way, the appeal for a partnership and the use of the sustainability design have led to the development of traditional commercial relationships, the primary purpose of which is not sustainability but profit maximization. Despite the above findings, this relationship was attributed to POM because it was found that the treatment of partnership changed the customer's perception in the service provider's concept of customer relationship. This means that in such groups, the mental recognition of partnership in commercial relations was one of the first steps in the transformation of classical commercial relations into a partnership organizational mechanism, which can then be used to achieve balance and sustainability. In other cases, the knowledge transfer POM model is used to inform and advise potential and existing LAG members on partnership issues.

The employment model (Figure 5) consists of Initiation, Direction, and Motivation. The essence of this model is defined by the definition-to inform in order to involve in participation. The auxiliary function of the information junction in the Inclusion and Participation processes was observed and the functional relationship between Participation and Inclusion was clearly identifiable. This model was typical to LAG, where local projects were implemented and where project working groups were formed. It should be noted that only a part of the projects were sustainability-oriented in their content. In other cases, the component of sustainability could only be identified through a more rational use of resources and they had easier access through a partnership.

The essence of the Communication model (Figure 6) is a complete integration of information mechanism focused on Direction, Initiation, and Introduction. This is a model that links POM to their inception and is typical of LAGs that are emerging or focusing on the development of a partnership network. Communication POM differs from Knowledge transfer POM in that in the case of Communication POM, information was a self-serving process, and in the case of Knowledge transfer POM, the purpose of information is to initiate consulting. Moreover, in case of Communication POM, the experience was observed when there was no fixed feedback in the information process, while in case of Knowledge transfer POM, not only did information initiate the sharing of knowledge, but also during the sharing of them, in specific cases, there was a return to information. Thus, from a longterm perspective in case of Knowledge transfer POM, a cyclic relationship was observed between information and consultation junctions.

The communication model was more typical to local government and was proactive, but there have also been instances of this being taken up by private individuals within LAG members.

A Motivation model (Figure 7), is like the Communication model identified in LAGs where local government has a proactive role. Its difference to the Communication model is that, in the motivation model, participation is not promoted through information, but through support. In this way, LAG members added value to the region through a participatory support mechanism, which is often associated with traditional commercial relationships disguised by partnership ideologies, where the customer is a local authority and the service provider is a member of LAG. What is unique in this relationship is that the commercial relationship, although partly imitated as a partnership, was recognized by both parties as a partnership. In addition, such a cooperation was not only focused 
on maximizing the profits inherent in classical commercial relations, but also had the characteristics of sharing resources, which made it possible to position it as a POM model.

\subsection{Balanced Models of POM Leading to Grater Sustainability}

A total of five POM models are classified as balanced (Engage in, Familiarization, Support, Inclusion, and Complete POM) (Figures 8-12). A complete POM model (Figure 12) differs from others in that all its shafts are active. Moreover, an empirical study found that Complete POM is characterized by two types of LAGs. Both types are similar in that they fulfil all the characteristics of the Complete POM model, but differ in that in some groups a high operational intensity in all junctions and shafts was observed, while in others there was detected a statistically significantly lower operational intensity compared to those with a high one. This suggests that POM models may differ not only in typological terms, but also in their intensity, which may indicate the degree of inclusion and the experience of LAG in POM.

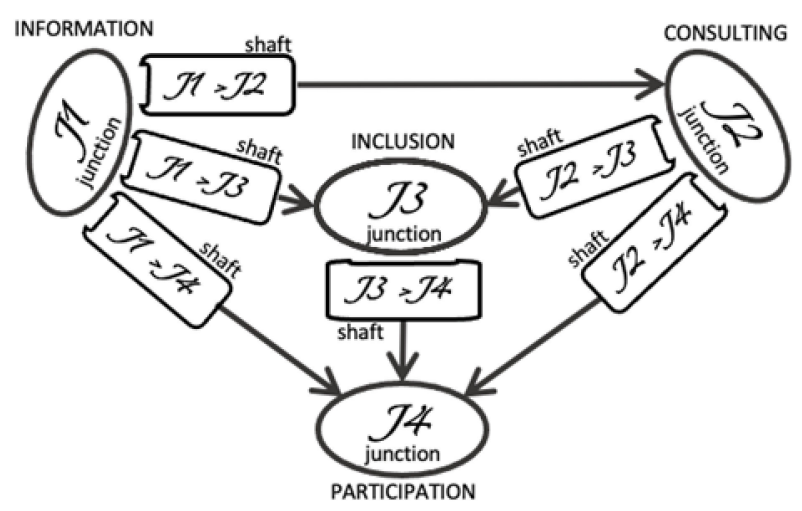

Figure 12. Complex POM model.

All active junctions holding in the Engage in POM model (Figure 8) are characterized by the fact that there are identified following ongoing processes Knowledge transfer, Introduction, Expression of opinion, Motivation, Presentation of an expert or specialist opinion, Advice on how to proceed, and Recommendation. All of them demonstrate the LAG's focus on inclusion and the procedural steps taken to introduce and impart the knowledge necessary to create inclusive preconditions for participation. This model has been recognized in LAGs that have experience in participating in POM. Furthermore, the knowledge of sustainability of this type of LAG matched with the nature of their partnership.

The Familiarization model (Figure 9) includes Direction, Expression of opinion, Recommendation, Advice on how to proceed, Motivation, Empowerment, Development of dialogue, Representation, and Discussion. It was typical to LAGs, whose main focus was on participation, and inclusion was not limited to creating motivation for participation, but was also based on the transfer of expertise to enable and realize participation.

In this type of LAG, a greater involvement of universities and colleges in POM processes was observed, and some LAGs functioned with minimal support from local government. In some LAGs, local authorities were involved in guiding and advising members in the POM.

The Familiarization POM model (Figure 9) combines LAGs active in project activities, whose members have a relatively high experience and knowledge, and Inclusion and Consulting are based on expert-level experience and deep knowledge of the operating environment, which may lead to the deactivation of Introduction and Initiation shafts.

The Support model (Figure 10) includes Introduction, Initiation, Expression of opinion, Knowledge Transfer, Recommendation, Advice on how to proceed, Presentation of an expert or specialist opinion, Development of dialogue, Discussion, Bringing together, Cooperation, and Motivation. It was typical to LAGs in which the give assistance function is strongly expressed. 
In the LAGs assigned to this model, the organization of activities observed is on a cyclical basis, i.e., the relationship between junctions was not only unidirectional linear to when the action of one junction or another is finite, but cyclicality due to feedback and repeated action of the junction was also identified. The existence of a cyclical relationship is related to the long-term relationship between LAG members. Relationships not only ensure continuity of the result, but at the same time increase the competence of members over time.

Long-term observation of LAGs assigned to the Support POM (see Figure 10) identified the Inclusion and Consulting junctions of the phenomenal feature of changing their influence to the Participation junction. This operation indicates that the performance of the POM can be optimized according to its need and purpose. This means that POM operation is not static and can be modified by making it more intensive or passive and by changing its component composition by enabling certain junctions and shafts in one cycle and disabling it in the other. Long-term observation has also identified that the latter feature is characteristic of more complex POM models in LAG, whose experience of participants is comparable to that of advanced ones.

The Involvement model (Figure 11) is characterized by Introduction, Direction, Presentation of an expert or specialist opinion, and Advice on how to proceed, Representation, development of dialogue, Empowerment, and Motivation. The LAG typical to this model was characterized by a high concentration of activity and the intensive involvement at all levels of management, looking from the perspective of an LAG organizational structure. LAGs, typical to this model, were characterized by a high level of focus and intensive involvement into operations at all levels of POM management. The specificity is that the lack of initiation and recommendation in the model can be considered to be a sign of the late development of LAG in a population where both human and other resources are limited and where the maximum level of involvement and sharing is close to the maximum. As the LAG approached its maximum potential and as its experience and professionalism of its members grew, the LAG operation observed was typical of the Involvement POM model.

This model shows that POM can not only change, but can also replicate the cycle of partnership development and the specifics of LAG member involvement and readiness. This feature is important in assessing the coherence of the LAG partnership and the level of participation experience, which was relatively higher during observation in cyclic models compared to linear POM models.

A Complex model (Figure 12) was detected in large LAGs whose experience is rated as advanced. It differs from other models in that in addition to all active junctions, all shafts are active. They are: Communication, Direction, Initiation, Introduction, Expression of opinion, Knowledge transfer, Recommendation, Advice on how to proceed, Presentation of an expert or specialist opinion, Information exchange, Development of dialogue, Representation, Discussion, Conciliation, Negotiation, Bringing together, Cooperation, Empowerment, Motivation, and Pooling of resources.

After detecting the Complex model (Figure 12) and studying the LAGs assigned to it, it was found that the experiences of their members were different. The experience of some members is comparable to that of experienced members, while others are just beginners. This finding shows that longer-functioning LAGs also integrate a growth function into the POM, which is designed to guarantee the long-term functionality of the POM without losing competencies as human resources change. This fact explains the purpose of shafts such as Initiation and Recommendation in POM. Their purpose is related to providing basic information and initial inclusion of members in LAG activities from which a participation begins.

When classifying LAGs, it was observed that the activity levels of junctions and shafts differed between the LAGs belonging to this model. Two types were detected whose activity differed statistically significantly, i.e., Active and Passive LAGs. Both types are identical in that all Junctions and Shafts within them have the same activity, i.e., in passive ones, all of their activity is low, and in active ones, it is high. This suggests that the POMs 
identified in LAG studies differ not only in their structure but also in their intensiveness of use.

\section{Discussion and Conclusions}

Sustainability as a goal in an empirical study led to the discovery of a variation in POMs between partnership as a goal and partnership as a means to achieve the goal. It turned out that some LAGs use partnerships to maximize profits, thus deviating from the concept of partnership, whereas others use sustainability only as an ideological construct to gain a competitive advantage for project financing. In such cases, no real investment is made in sustainability. It becomes only a declarative position for the absorption of financial resources. It becomes only a declarative position to attract outside financing. Another extreme that emerged during the study was the hyper orientation to partnership as a goal. In this case, the result was also not sustainability itself, but was used as an ideological tool to build a partnership. In this way, has imitated the activity of sustainability. The process was needed to obtain funding to build physical infrastructure and to create a vision for the partnership, but the partnership was not realized because no funds were allocated to it. A situation has arisen where investments have been directed towards a partnership without a future partnership.

The POM model demonstrated its potential for ensuring the viability of areas when the LAG sought a balance between partnership and sustainability. In the POM model, to sustainability has been assigned the roles of organizing and helping to coordinate all initiatives and making them targeted. The partnership under the POM model was used to maximize the efficiency of the effort required for the productive participation of LAG members. POM models not only were typologically diverse, but were also allowed to be controlled during LAG development as functions that evolved from one POM type to another. This enabled the POM cyclic transformation process, which allowed the LAG to modify and control the POM structure by enabling necessary and disabling unnecessary functions, thus increasing fragmentation or achieving total complexity. Observing this phenomenon, it was observed that the complexity of the use of formal functions depends on the goals of the LAG and the mission performed. As they changed, so did the structure and functionality of POM.

The study also identified that the Information, Consulting, and Inclusion junctions of the model functions as a productivity moderator. Intensifying and changing the content of Information, Consulting, and Inclusion junctions' productivity of participation can be increased, especially in cases where POM forms a feedback between junctions. In this way, the POM transforms from a linear model into a cyclic model in which internal cycles between individual junctions are combined into a complex cyclic model designed to provide knowledge exchange and feedback between all junctions.

Although only formal POMs have been empirically studied, it should be noted that the POM operation has demonstrated the flexibility and possibility to apply POM to informal organizational relationships that allow the development of informal POMs.

The secondary result of the empirical study and long-term observation is that the same type of POM belonging to LAGs have had a similar organizational culture and they tended to merge into one.

A phenomenon was observed when LAGs of similar cultures encountered external threats, i.e., when the population of the represented territory decreased to the limit when the EU minimum threshold was not reached, only LAGs of a similar culture successfully has been merged into one LAG, together merging POMs with different functions into a single POM where all these functions were successfully coordinated. This suggests that POM can be transformed according to the specifics of LAG activities and when LAG faces environmental challenges.

Summarizing, LAG is not only different in terms of its POM, but can also modify it to adapt POM to LAG's needs. This indicates that the POM structure can be designed, 
managed and rearranged, thus achieving the optimal performance of the POM required to ensure the sustainable operation of the LAG.

Author Contributions: Conceptualization-V.A. and E.S.; Formal analysis—S.V.; Investigation-V.A., S.V. and E.S.; Methodology-S.V.; Resources-E.S.; Supervision-V.A.; Validation-S.V.; VisualizationS.V.; Writing-original draft-V.A., S.V. and E.S. All authors have read and agreed to the published version of the manuscript.

Funding: This research received no external funding.

Institutional Review Board Statement: Not applicable.

Informed Consent Statement: Not applicable.

Data Availability Statement: Not applicable.

Conflicts of Interest: The authors declare no conflict of interest.

\section{References}

1. Mathis, K.A.; Bronstein, J.L. Our Current Understanding of Commensalism. Annu. Rev. Ecol. Evol. Syst. 2020, 51, 167-189. [CrossRef]

2. Roostaie, S.; Nawari, N.; Kibert, C. Integrated sustainability and resilience assessment framework: From theory to practice. J. Clean. Prod. 2019, 232, 1158-1166. [CrossRef]

3. Linnenluecke, M.K. Resilience in business and management research: A review of influential publications and a research agenda. Int. J. Manag. Rev. 2015, 19, 4-30. [CrossRef]

4. Lew, A.A.; Ng, P.T.; Ni, C.-C.; Wu, T.-C. Community sustainability and resilience: Similarities, differences and indicators. Tour. Geogr. 2015, 18, 18-27. [CrossRef]

5. Xu, L.; Marinova, D.; Guo, X. Resilience thinking: A renewed system approach for sustainability science. Sustain. Sci. 2015, 10, 123-138. [CrossRef]

6. Vaitkevicius, S.; Papsiene, P.; Vaitkevicius, J.V. Rethinking a timely response of human resources to global signals: A case of organizational reflexes. Eng. Econ. 2021, 32, 48-59. [CrossRef]

7. Linnenluecke, M.K.; McKnight, B. Community resilience to natural disasters: The role of disaster entrepreneurship. J. Enterprising Communities People Places Glob. Econ. 2017, 11, 166-185. [CrossRef]

8. Kanie, N.; Biermann, F. Governing through Goals: Sustainable Development Goals as Governance Innovation; Mit Press: Cambridge, MA, USA, 2017.

9. Xu, L.; Marinova, D.; Xin, P.; Guo, X. Resilience-Based sustainability indicators for freshwater lakes with application for Dongting Lake, China. Environ. Nat. Resour. Res. 2015, 5, 165. [CrossRef]

10. George, R.A.; Siti-Nabiha, A.; Jalaludin, D. Sustainability institutionalisation: A mechanistic approach to control change. J. Clean. Prod. 2018, 205, 36-48. [CrossRef]

11. Arenas, A.; Díaz-Guilera, A.; Kurths, J.; Moreno, Y.; Zhou, C. Synchronization in complex networks. Phys. Rep. 2008, 469, 93-153. [CrossRef]

12. Stareike, E. Partnerystes Organizacinio Mechanizmo Fenomenas Vietos Veiklos Grupeje (The Phenomenon of the Partnership Organisational Mechansm in Local Action Group). Ph.D. Dissertation, Aleksandras Stulginskis University, Akademija, Lithuania, 2017.

13. Jackson, M.O. Mechanism Theory; EOLSS: Oxford, UK, 2003.

14. Hurwicz, L. The design of mechanisms for resource allocation. Am. Econ. Rev. 1973, 63, 1-30.

15. Maskin, E.; Sjostrom, T. Implementation theory. In Handbook of Social Choice Theory; Arrow., K., Sen., A., Suzumura, K., Eds.; North Holland: Amsterdam, The Netherlands, 2002; Volume I, pp. 237-288. Available online: https://scholar.harvard.edu/files/ maskin/files/implementation_theory_published_version.pdf (accessed on 7 December 2020).

16. Baliga, S.; Maskin, E. Mechanism Design for the Environment. In Handbook of Environmental Economics; Mäler, K.G., Vincent, J., Eds.; North-Holland: Amsterdam, The Netherlands, 2003; Volume 1.

17. Maskin, E.S. Mechanism design: How to implement social goals. Am. Econ. Rev. 2008, 98, 567-576. [CrossRef]

18. Lebel, L.; Anderies, J.; Campbell, B.; Folke, C.; Hatfield-Dodds, S.; Hughes, T.; Wilson, J. Governance and the capacity to manage resilience in regional social-ecological systems. Ecol. Soc. 2006, 11, 19. [CrossRef]

19. Grandori, A.; Furnari, S. A chemistry of organization: Combinatory structural analysis and design. Organ. Stud. 2008, 29, 459-485. [CrossRef]

20. Grandori, A. Democratic governance and the firm. Rev. Adm. 2017, 52, 353-356. [CrossRef]

21. Anderson, P.J.J.; Blatt, R.; Christianso, M.K.; Grant, A.M.; Marquis, C.; Neuman, E.J.; Sonenshein, S.; Sutcliffe, K.M. Understanding mechanisms in organizational research: Reflections from a collective journey. J. Manag. Inq. 2006, 15, 102-113. [CrossRef]

22. Mechkour, S. Overview of Situation Theory and Its Application in Modelling Context; Seminar Paper; Department of Informatics, University of Fribourg: Fribourg, Switzerland, 2007. 
23. Hedstrom, P.; Swedberg, R. Social mechanisms. In An Analytical Approach to Social Theory; Cambridge University Press: Cambridge, UK, 1998.

24. Stinchcombe, A.L. The conditions of fruitfulness of theorizing about mechanisms in social science. Philos. Soc. Sci. 1991, 21, 367-388. [CrossRef]

25. Weber, M. Bureaucracy. In Working in America; Routledge: London, UK, 2015; pp. 29-34.

26. King, D.C.; Bennis, W.G.; Schein, E.H.; Berlew, D.E.; Steele, F.I. Interpersonal dynamics: Essays and readings on human interaction. ILR Rev. 1965, 19, 143. [CrossRef]

27. McNally, J. The Functions of the Executive, by Chester Barnard; Harvard University Press: Cambridge, MA, USA, 1938.

28. Simon, H.A. Administrative Behavior; Simon and Schuster: New York, NY, USA, 2013.

29. Leach, W.D.; Pelkey, N.W.; Sabatier, P.A. Stakeholder partnerships as collaborative policymaking: Evaluation criteria applied to watershed management in California and Washington. J. Policy Anal. Manag. 2002, 21, 645-670. [CrossRef]

30. Glasbergen, P.; Biermann, F.A.; Mol, P.J. Partnerships, Governanceand Sustainable Development: Reflections on Theory; Edward Elgar Publishing: Cheltenham, UK, 2007.

31. Van Huijstee, M.M.; Francken, M.; Leroy, P. Partnerships for sustainable development: A review of current literature. Environ. Sci. 2007, 4, 75-89. [CrossRef]

32. Greve, C.; Hodge, G. Public-private partnerships and public governance challenges. In The New Public Governance: Emerging Perspectives on the Theory and Practice of Public Governance; Routledge: London, UK, 2010; pp. 149-162. [CrossRef]

33. McQuaid, R. Theory of Organizational Partnerships: Partnership advantages, disadvantages and success factors. In The New Public Governance? Emerging Perspectives on the Theory and Practice of Public Governance; Osborn, S.P., Ed.; Routledge: London, UK, 2010; pp. 127-148.

34. Benington, J.; Geddes, M. Local Partnership and Social Exclusion in the European Union: New Forms of Local Social Governance? Routledge: London, UK, 2013.

35. Mohr, J.; Spekman, R. Characteristics of partnership success: Partnership attributes, communication behavior, and conflict resolution techniques. Strat. Manag. J. 1994, 15, 135-152. [CrossRef]

36. Macken-Walsh, Â.; Curtin, C. Governance and rural development: The case of the rural partnership programme (rpp) in post-socialist lithuania. Sociol. Rural. 2013, 53, 246-264. [CrossRef]

37. Fernandez-Gimenez, M.; Augustine, D.J.; Porensky, L.M.; Wilmer, H.; Derner, J.; Briske, D.D.; Stewart, M.O. Complexity fosters learning in collaborative adaptive management. Ecol. Soc. 2019, 24, 21. [CrossRef]

38. Sisto, R.; Lopolito, A.; van Vliet, M. Stakeholder participation in planning rural development strategies: Using backcasting to support Local Action Groups in complying with CLLD requirements. Land Use Policy 2018, 70, 442-450. [CrossRef]

39. Cronwall, A. Making Spaces, Changing Places: Situating Participation in Development. 2002. Available online: https://opendocs. ids.ac.uk/opendocs/bitstream/handle/123456789/3932/Wp170.pdf (accessed on 3 May 2021).

40. Bueret, J.E. Biodiversity and stakeholders: Concertation itineraries. In Dialogue and Concertation in Biosfere Reserves: Issues and Challenges; Technical Notes: London, UK, 2006.

41. Gone, J.P. Research reservations: Response and responsibility in an american indian community. Am. J. Community Psychol. 2006, 37, 183-189. [CrossRef] 